\title{
Cerebrospinal Fluid Corticotropin-Releasing Factor (CRF) and Vasopressin Concentrations Predict Pituitary Response in the CRF Stimulation Test: A Multiple Regression Analysis
}

\author{
D Jeffrey Newport', Christine Heim', Michael J Owens', James C Ritchie', Clayton H Ramsey', Robert \\ Bonsall', Andrew H Miller' and Charles B Nemeroff*', \\ 'Department of Psychiatry and Behavioral Sciences, Emory University School of Medicine, Atlanta, GA, USA
}

\begin{abstract}
There is considerable evidence that stress-related psychiatric disorders, including depression and post-traumatic stress disorder (PTSD), are associated with hypersecretion of corticotropin-releasing factor (CRF) within the central nervous system (CNS). One line of evidence that is consistent with central CRF hypersecretion in these disorders is the blunted adrenocorticotropin hormone (ACTH) response to intravenous CRF administration, likely a consequence, at least in part, of downregulation of anterior pituitary CRF receptors. The present study tests the hypothesis that elevated cerebrospinal fluid (CSF) concentrations of CRF and a secondary ACTH secretagogue, arginine vasopressin (AVP), are associated with diminished adenohypophyseal responses in a standard CRF stimulation test. CSF concentrations of CRF and AVP, and plasma ACTH responses to the administration of $1 \mu \mathrm{g} / \mathrm{kg}$ ovine CRF (oCRF) were measured in healthy adult women with and without current major depression and/or a history of significant childhood abuse. The primary outcome measure was ACTH area under the curve (AUC) in the CRF stimulation test. Multiple linear regression was performed to identify the impact of CSF CRF and AVP concentrations upon the pituitary response to CRF stimulation. The regression model explained $56.5 \%$ of the variation in the ACTH response to CRF stimulation. The relationship of CSF concentrations of CRF to ACTH responses to CRF were best described by a third-order function that was inversely correlated over most of the range of studied values. The association of ACTH response with CSF concentration of AVP and the dose of oCRF followed second-order kinetics. These findings support the hypothesis that central CRF hypersecretion is associated with a blunted ACTH response to exogenously administered CRF, explaining almost 60\% of the variation in the ACTH response to CRF.
\end{abstract}

Neuropsychopharmacology (2003) 28, 569-576. doi: I 0.1038/sj.npp. I30007|

Keywords: corticotropin-releasing factor; vasopressin; cerebrospinal fluid; hypothalamic-pituitary-adrenal axis; depression; PTSD

\section{INTRODUCTION}

Considerable evidence has accrued over the last three decades implicating corticotropin-releasing factor (CRF) as the preeminent regulator of the mammalian response to stress (cf Newport and Nemeroff, 2001 for a review). Indeed, dysfunction in CRF neuronal systems is believed to be critical to the etiopathogenesis of numerous stress-related disorders including major depressive disorder (MDD) and post-traumatic stress disorder (PTSD) (Nemeroff, 1996; Keck and Holsboer, 2001). In support of this hypothesis,

\footnotetext{
*Correspondence: Dr CB Nemeroff, Department of Psychiatry and Behavioral Sciences, Emory University School of Medicine, Woodruff Memorial Research Building, 1639 Pierce Drive, Suite 4000, Atlanta, GA 30322, USA, Tel: +I 404772 8382, Fax: +I 404727 3233, E-mail: cnemero@emory.edu

Received 4 June 2002; revised 6 September 2002; accepted II September 2002

Online publication: 24 September 2002 at http://www.acnp.org/ citations/Npp092402390
}

standard hypothalamic-pituitary-adrenal (HPA) axis challenge tests, such as the CRF stimulation test, have been utilized as peripheral 'neuroendocrine windows' (Plotsky et $a l, 1998)$ to surmise the activity of hypothalamic CRF neuronal systems.

A blunted adrenocorticotropin hormone (ACTH) response in the CRF stimulation test has repeatedly been reported in patients with MDD (Gold et al, 1984; Holsboer et al, 1987; Amsterdam et al, 1988; Kathol et al, 1989; Heim et al, 2001) and PTSD (Smith et al, 1989; Young et al, 1990; Heim et al, 1997, 2001). It has been suggested that this diminished ACTH response to exogenous CRF is a consequence of chronic hyperactivity of CRF-secreting neurons in the hypothalamic paraventricular nucleus that induces a downregulation of CRF receptors at the adenhohypophysis. In addition, hypothalamic secretion of arginine vasopressin (AVP), an important co-secretagogue of pituitary ACTH, may likewise influence patterns of pituitary response to CRF stimulation (Scott and Dinan, 1998). Despite the hypothesis that the blunted ACTH response in 
the CRF stimulation test is a result of central CRF hypersecretion, this hypothesis has never been formally tested in a clinical sample. The aim of the present study was to test the hypothesis that central hypersecretion of CRF, and possibly AVP, is associated with diminished ACTH responsivity in the CRF stimulation test.

\section{METHOD}

\section{Participants}

The study sample was comprised of a heterogeneous assortment of adult women: with or without a history of significant childhood sexual or physical abuse, and with or without current MDD or PTSD. This diverse sample was collected in an effort to delineate the association between the candidate predictor variables and the primary outcome variable over the range of HPA axis activity commonly observed in healthy volunteers and those with psychiatric illness. All women were in their reproductive years and reported regular menstrual cycles. General exclusion criteria were pregnancy or lactation, significant medical illness, any history of psychotic symptoms or bipolar disorder, active substance use disorder or eating disorder within 6 months, or current treatment with psychotropic or hormonal medications (except oral contraceptives). All subjects were recruited from responses to newspaper advertising and were remunerated for participation. After a complete description of the study to the subjects, written informed consent was obtained. The Emory University School of Medicine Institutional Review Board approved the study protocol.

\section{Clinical Procedures}

Psychometric evaluation included the Structured Clinical Interview for DSM-IV (SCID) (First et al, 1997) for the diagnosis of MDD, PTSD, and other psychiatric disorders. In addition, the semistructured early trauma inventory (ETI) was utilized to assess the presence and severity of childhood trauma, including physical, sexual, and emotional child abuse or neglect (Bremner et al, 2000).

Participants were admitted at 10:00 am to the NIH-funded General Clinical Research Center at Emory University Hospital and remained at bed rest with no oral intake except water beginning $2 \mathrm{~h}$ before and throughout all test procedures. On day 1 of hospitalization, an experienced faculty member of the Department of Anesthesiology at Emory University performed lumbar puncture at 4:00 pm using standard aseptic technique. A 4-6 ml cerebrospinal fluid (CSF) sample was collected, transferred to coded $1 \mathrm{ml}$ aliquot tubes, and stored at $-80^{\circ} \mathrm{C}$ until assay.

The CRF stimulation test was performed on day 2 of hospitalization. An intravenous catheter was inserted into a forearm vein at 12:00 pm, and patency was maintained by slow saline infusion. Venous blood samples were collected at 30-min intervals from 1:30 until 4:00 pm to obtain baseline hormonal measures. At 4:00 pm, $1 \mu \mathrm{g} / \mathrm{kg}$ ovine CRF (oCRF) was administered through the intravenous catheter. Venous blood samples were collected at 5, 15, 30, 60, 90, and 120 min after oCRF administration. All blood samples were collected in chilled EDTA-containing tubes, placed imme- diately on ice, and centrifuged at $4{ }^{\circ} \mathrm{C}$ for $10 \mathrm{~min}$ at $3000 \mathrm{rpm}$. Plasma was separated, coded, and stored at $-80^{\circ} \mathrm{C}$ until assay.

\section{Laboratory Assays}

Laboratory personnel masked to subject demographics and sample sequence conducted all neuroendocrine assays. Concentrations of CSF CRF were measured in duplicate $450-\mu \mathrm{l}$ aliquots that were lyophilized, reconstituted in $200 \mu \mathrm{l}$ assay buffer, and incubated at $4^{\circ} \mathrm{C}$ for $18 \mathrm{~h}$ with $100 \mu \mathrm{l}$ antiserum (oC33) raised in rabbits against oCRF at a final dilution of $1: 21875$ in assay buffer containing 1\% normal rabbit serum. Radiolabeled $\left[{ }^{125} \mathrm{I}\right] \mathrm{Tyr}^{0}$-rat/human CRF (20000 cpm in $50 \mu \mathrm{l}$ buffer) was then added to each tube. After incubation for $24 \mathrm{~h}$ at $4^{\circ} \mathrm{C}, 10 \mu \mathrm{l}$ goat anti-rabbit serum was added to precipitate bound CRF. The standards containing $450 \mu \mathrm{l}$ artificial CSF and 0.625-640 pg CRF/tube were prepared using rat/human CRF and were treated identically as the human CSF samples. The sensitivity of the assay was $1.25 \mathrm{pg} /$ tube, with $50 \%$ displacement of radiolabeled CRF $\left(\mathrm{IC}_{50}\right)$ at $30 \mathrm{pg} /$ tube. The inter- and intra-assay coefficients of variation have been measured every 6 months for the past 15 years with a set of identical samples (pooled human CSF) in two separate assays. The difference between these values has ranged from 10 to $13 \%$ for interassay measurements and from 2 to $6 \%$ for intra-assay measurements over this period of time.

The AVP assay utilized synthetic standard material ( $\mathrm{Arg}^{8}$ Vasopressin: Bachem, Torrance, CA). Iodinated vasopressin was prepared in our laboratory via Chloramine $\mathrm{T}$ oxidation and high-pressure liquid chromatography (HPLC) purification. Standard curves were prepared in artificial CSF, and two CSF pools were used as quality control preparations. Prior to assay, standards, controls, and samples were extracted on C-18 Sep Paks (Waters, Milford, MA). The extracts were then concentrated by lyophilization and reconstituted in assay buffer. They were subsequently incubated with the primary antisera at $4{ }^{\circ} \mathrm{C}$ for $24 \mathrm{~h}$. After addition of the tracer, the extracts were incubated for an additional $24 \mathrm{~h}$. A second antibody, goat anti-rabbit gamma globulin, was then added with a 1:5 dilution of normal rabbit serum to induce precipitation, and the incubation continued for an additional $3 \mathrm{~h}$. After separating the bound component by centrifugation, the tubes were decanted and counted in a gamma counter. The working sensitivity of the assay is $0.3 \mathrm{pg} / \mathrm{ml}$. The intra- and interassay coefficients of variation were 5 and $9 \%$, respectively.

Plasma samples from the CRF stimulation test were assayed for ACTH and cortisol concentrations using sensitive commercial radioimmunoassays (ACTH: Nichols, San Juan Capistrano, CA; cortisol: DiaSorin, Stillwater, $\mathrm{MN})$. The intra- and interassay coefficients of variation were 4.5 and $6.3 \%$, respectively, for ACTH, and 3.8 and $7.3 \%$, respectively, for cortisol. Assay sensitivities were $0.5 \mathrm{pg} / \mathrm{ml}$ for ACTH and $0.18 \mu \mathrm{g} / \mathrm{dl}$ for cortisol.

\section{Statistical Analysis}

Descriptive analysis of demographic and clinical data was conducted using frequency tests for categorical and ordinal data, and calculation of sample means and standard 
deviations for continuous data. A multiple regression analysis was then performed with assumptions of normality, linearity, and homoscedasticity between predicted outcome variable values and errors of prediction (Kleinbaum et al, 1998). The primary outcome variable, ACTH area under the curve $\left(\mathrm{ACTH}_{\mathrm{AUC}}\right)$ after oCRF administration, was calculated relative to baseline plasma ACTH concentration using the trapezoidal rule. Since the initial descriptive analysis revealed the distribution of $\mathrm{ACTH}_{\mathrm{AUC}}$ measures to be positively skewed, the dependent variable was normalized via logarithmic transformation. The Shapiro-Wilks test (Shapiro and Wilks, 1965), an appropriate test of normality for small sample sizes (Kleinbaum et al, 1998), demonstrated that post-transformation residuals were normally distributed $(w=0.9791, p=0.6575)$.

For the establishment of a stable regression model, four candidate predictor variables were identified: CRF concentration in cerebrospinal fluid $\left(\mathrm{CRF}_{\mathrm{CSF}}\right), \mathrm{AVP}$ concentration in cerebrospinal fluid $\left(\mathrm{AVP}_{\mathrm{CSF}}\right)$, baseline plasma cortisol

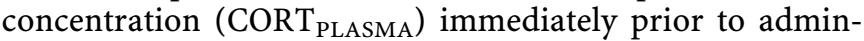
istration of oCRF, and dose of oCRF administered $\left(\mathrm{oCRF}_{\text {DOSE }}\right)$. CORT $\mathrm{CLASMA}_{\text {PLA }}$ wancluded in the model as a crude index of glucocorticoid feedback activity within the HPA axis. Although the oCRF DOSE $_{\text {utilized in the study was }}$ body weight-adjusted in an effort to standardize HPA axis stimulation, we were uncertain as to whether this modification would produce proportional results over the range of body weights of the study participants. Consequently, $\mathrm{oCRF}_{\mathrm{DOSE}}$ was also included as a candidate predictor in the model. Since the kinetics of HPA axis activity are poorly understood, and because numerous studies indicate that various aspects of HPA axis function may best fit quadratic or higher-order polynomial functions (Hanada et al, 1985; Kemppainen et al, 1986; Dellwo and Beauchene, 1990; Coppinger et al, 1991; Kosowska, 1992; Apple et al, 1993; Kling et al, 1993), we included squared and cubed polynomials of each candidate predictor in addition to product interaction terms between each of the primary predictors in the model. To eliminate the inherent tendency for multicollinearity in polynomial models, each of the candidate predictor variables was converted to an orthogonal polynomial. A backward elimination procedure with $\alpha=0.10$ for retention was used to determine the predictor variables in the final model. A candidate predictor was retained if a higher-order polynomial of the variable or a product interaction term containing the variable was statistically significant. The condition number $(\mathrm{CN}=8.03)$ of the final model indicates that there is little potential for significant collinearity. A stable estimate of parameters in the regression analysis can therefore be assumed.

Since oral contraceptives have been associated with altered HPA axis measures including lower concentrations of ACTH (Carr et al, 1979; Nickelsen et al, 1989), elevated concentrations of cortisol (Carr et al, 1979; Nickelsen et al, 1989; Meulenberg and Hofman, 1990) and cortisol binding globulin (Bulbrook et al, 1973; Carr et al, 1979; Carol et al, 1980; Fujimoto et al, 1986; Kirschbaum et al, 1999), and diminished salivary cortisol responses to various stressors (Kirschbaum et al, 1995, 1996, 1996), the holdout sample approach (Kleinbaum et al, 1998) was used to assess the impact of oral contraceptive use upon the reliability of the model. To implement this approach, a second regression analysis was performed using the same dependent variable and predictor variables against the holdout sample of participants who were not taking oral contraceptives. Shrinkage on cross-validation was then calculated by subtracting the squared correlation $\left(R^{2}\right)$ of the predicted $v s$ observed outcome values in the model of the full sample from the squared correlation $\left(R^{2}\right)$ of the predicted $v s$ observed outcome values in the model of the holdout sample. A shrinkage of less than $10 \%$ (Kleinbaum et al, 1998) was determined a priori as the threshold to indicate whether oral contraceptive use compromised the reliability of the regression model.

\section{RESULTS}

\section{Descriptive Data}

A total of 47 subjects were enrolled and completed all aspects of the study. Of these 47 enrolled patients, two were excluded because there was an insufficient CSF volume to assay both CRF and AVP, four were excluded due to missing data in the CRF stimulation test, and one was excluded due to outlying values in the CRF stimulation test (ie ACTH concentrations after oCRF administration were lower than baseline ACTH concentrations, indicating a probable procedural error in conducting the test).

Table 1 presents a descriptive summary of the demographic and clinical characteristics of the remaining 40 participants. Of note, the study participants were evenly distributed between those with a history of child abuse $(n=21,52.5 \%)$ and those with no history of child abuse $(n=19,48.5 \%)$. Similarly, approximately one-half had no current psychiatric illness $(n=18,45 \%)$ while the remainder $(n=22,55 \%)$ fulfilled DSM-IV criteria for MDD, PTSD, or both. None of the study participants were receiving any psychotropic medications, and only three of the 40 subjects had discontinued any psychopharmacological agent in order to participate. In those subjects, psychotropic medicines were discontinued a minimum of 2 weeks prior to initiation of any study procedures (6 weeks earlier for fluoxetine). Seven of the 40 subjects were receiving oral contraceptives during the study. Table 2 presents the mean and standard deviation of the dependent variable $\left(\mathrm{ACTH}_{\mathrm{AUC}}\right)$ and each of the candidate predictor variables.

\section{Multiple Regression Analysis}

The results of the multiple regression analysis are presented in Table 3 and Figure 1. As anticipated, the correlation of the predictor variables with $\mathrm{ACTH}_{\mathrm{AUC}}$ was predicted by polynomial rather than simple linear functions. As a whole, the linear, quadratic, and cubic functions of $\mathrm{CRF}_{\mathrm{CSF}}$ explained $22.8 \%$ of the variability in $\mathrm{ACTH}_{\mathrm{AUC}}(\mathrm{F}=6.04$, $\mathrm{df}=3, p=0.0023)$. Two of the three $\mathrm{CRF}_{\mathrm{CSF}}$ terms in the model $\left(\mathrm{CRF}_{\mathrm{CSF}}, \mathrm{CRF}_{\mathrm{CSF} 3}\right)$ are inversely correlated with $\mathrm{ACTH}_{\mathrm{AUC}}$. The relationship of $\mathrm{ACTH}_{\mathrm{AUC}}$ with both $\mathrm{AVP}_{\mathrm{CSF}}$ and $\mathrm{OCRF}_{\mathrm{DOSE}}$ is best described by quadratic functions. $\mathrm{AVP}_{\mathrm{CSF}}$ and $\mathrm{AVP}_{\mathrm{CSF}}^{2}$ explain $15.0 \%$ of the variation in $\mathrm{ACTH}_{\mathrm{AUC}}(\mathrm{F}=3.84, \mathrm{df}=2, p=0.0323) . \quad \mathrm{oCRF}_{\mathrm{DOSE}}$ and $\mathrm{OCRF}_{\mathrm{DOSE}}^{2}$ explain $12.2 \%$ of the variation in $\mathrm{ACTH}_{\mathrm{AUC}}$ $(\mathrm{F}=5.54, \mathrm{df}=2, p=0.0088)$. Although the first-order term $\mathrm{OCRF}_{\text {DOSE }}(p=0.1374)$ did not meet the significance criteria 
Table I Demographic and Clinical Characteristics of Study Participants $(n=40)$

\begin{tabular}{|c|c|}
\hline Variable & $\begin{array}{l}\text { Mean (SD) } \\
\text { or } N(\%)\end{array}$ \\
\hline Age (mean, SD) & $30.9(8.2)$ \\
\hline \multicolumn{2}{|l|}{ Race $(n, \%)$} \\
\hline African-American & $12(30.0)$ \\
\hline White & $27(67.5)$ \\
\hline Asian & I (2.5) \\
\hline Weight (kg) (mean, SD) & $75.7(24.8)$ \\
\hline \multicolumn{2}{|l|}{ Marital status (n, \%) } \\
\hline Single (never married) & $20(50.0)$ \\
\hline Married or cohabitating & II (27.5) \\
\hline Divorced & $9(22.5)$ \\
\hline \multicolumn{2}{|l|}{ Education ( $n, \%)$} \\
\hline Did not graduate high school & I (2.5) \\
\hline High school or equivalency & $4(10.0)$ \\
\hline Attended college & $14(35.0)$ \\
\hline $2 / 4$ year college degree & $13(32.5)$ \\
\hline Attended graduate school & $8(20.0)$ \\
\hline \multicolumn{2}{|l|}{ History of child abuse $(n, \%)$} \\
\hline Sexual abuse only & $10(25.0)$ \\
\hline Physical abuse only & $2(5.0)$ \\
\hline Sexual and physical abuse & $9(22.5)$ \\
\hline Total & $21(52.5)$ \\
\hline \multicolumn{2}{|l|}{ Diagnosis (n, \%) } \\
\hline None & $18(45.0)$ \\
\hline MDD only & $10(25.0)$ \\
\hline PTSD only & $6(15.0)$ \\
\hline MDD and PTSD & $6(15.0)$ \\
\hline \multicolumn{2}{|l|}{ Medication use $(n, \%)$} \\
\hline Taking psychiatric medicine & $0(0.0)$ \\
\hline Taking oral contraceptive & $7(17.5)$ \\
\hline
\end{tabular}

Table 2 Descriptive Summary of Outcome Variable and Candidate Predictor Variables

\begin{tabular}{|c|c|c|}
\hline Variable & Mean (SD) & Units \\
\hline \multicolumn{3}{|l|}{ Outcome variable } \\
\hline ACTH area under curve $\left(\mathrm{ACTH} \mathrm{A}_{\mathrm{AUC}}\right)$ & $5278.30(3035.79)$ & $(\mathrm{pg} \min ) / \mathrm{ml}$ \\
\hline \multicolumn{3}{|l|}{ Predictor variables } \\
\hline CRF in cerebrospinal fluid (CRF & $25.62(12.43)$ & $\mathrm{pg} / \mathrm{ml}$ \\
\hline AVP in cerebrospinal fluid (AVP $\left.\mathrm{PSF}_{\mathrm{CS}}\right)$ & $3.14(1.22)$ & $\mathrm{pg} / \mathrm{ml}$ \\
\hline Baseline plasma cortisol (CORT PLASMA) & $6.15(2.79)$ & $\mu g / d$ \\
\hline Dose of ovine CRF (oCRF & $75.68(24.79)$ & $\mu \mathrm{g}$ \\
\hline
\end{tabular}

$(\alpha=0.10)$, it was retained in the final model because the higher-order polynomial oCRF DOSE $^{2}$ was significant $(p=0.0035)$. Since they were not statistically significant predictors of the variability in $\mathrm{ACTH}_{\mathrm{AUC}}$, each of the polynomial CORT $_{\text {PLASMA }}$ terms were eliminated from the model. The total model, including a product term to depict the interaction of $\mathrm{CRF}_{\mathrm{CSF}}$ and $\mathrm{AVP}_{\mathrm{CSF}}$, was highly significant $(\mathrm{F}=5.03, \mathrm{df}=8, \quad p=0.0005)$ and explained $56.5 \%$ of the variation in the outcome variable $\mathrm{ACTH}_{\mathrm{AUC}}$.
The regression model constructed from the holdout sample of those subjects who were not receiving oral contraceptives $(n=33)$ was also highly significant $(\mathrm{F}=4.31$, $\mathrm{df}=8, \quad p=0.0025)$. The shrinkage on cross-validation between the full sample and the holdout sample was only $1.42 \%$, indicating that the reliability of the model was not impacted by oral contraceptive use.

\section{DISCUSSION}

Clinical research often relies upon minimally invasive, peripheral measures to provide a 'neuroendocrine window' for drawing conclusions regarding brain function and dysfunction. It is imperative, therefore, that the interpretations derived from these peripheral indices be subjected to confirmation whenever possible. Animal models utilizing invasive techniques that can rarely be implemented in human subjects are often used in this confirmatory manner. For example, a recent rodent study confirmed the hypothesis that diminished CRF receptor binding in the anterior pituitary is associated with a blunted ACTH response to CRF stimulation (Hauger et al, 2002). Preclinical data is certainly informative; however, its utility is limited by the incomplete homology of any animal model for the human condition (Newport et al, 2002).

The key finding in this study is the confirmation that the CSF concentration of CRF is inversely correlated with pituitary responsiveness to CRF as evidenced by $\mathrm{ACTH}_{\mathrm{AUC}}$ during the CRF stimulation test. Although the model depicts a complex association following third-order kinetics that is further obscured by the interaction of CRF with AVP, ACTH responses are generally diminished as $\mathrm{CRF}_{\mathrm{CSF}}$ rises across the range of studied values. This finding notably lends credence to the common inference that blunted ACTH responses to CRF stimulation are a consequence of chronic CRF hypersecretion.

The association between $\mathrm{CRF}_{\mathrm{CSF}}$ and $\mathrm{ACTH}_{\mathrm{AUC}}$ appears to contradict the widespread conviction that CSF CRF collected by lumbar puncture principally originates from extra-hypothalamic sources. Whereas it is generally accepted that pituitary ACTH secretion is stimulated by CRF secreted by neurons emanating from the parvocellular nucleus of the hypothalamus (Lennard et al, 1993), the absence of a correlation between the diurnal cycles of CSF CRF and plasma cortisol concentrations (Garrick et al, 1987; Kalin et al, 1987; Geracioti et al, 1997; Kling et al, 1994) is believed to indicate that most CSF CRF does not originate from the hypothalamus. Given the lengthy transit flow time of CSF through the central nervous system (CNS), the 10min half-life of CRF within CSF suggests that a preponderance of the CRF present in lumbar CSF is secreted by the spinal cord (Geracioti et al, 1997). This is consistent with evidence of a craniocaudal CRF gradient in the CSF of suicide victims (Arato et al, 1989).

Lumbar CRF studies may nevertheless be a reliable index of CRF neuronal function at higher centers within the CNS. For example, CRF concentrations in lumbar CSF were highly correlated to those in cisternal CSF (Geracioti et al, 1997). Furthermore, because active transport mechanisms may exist to rapidly clear CRF and other neuropeptides from the cerebral ventricles to lower regions of the CNS 
Table 3 Results of Multiple Regression Analysis with the Natural Logarithm of the Area under the Curve of Plasma ACTH Concentration in Response to Exogenous Ovine CRF as the Outcome Variable $(n=40)$

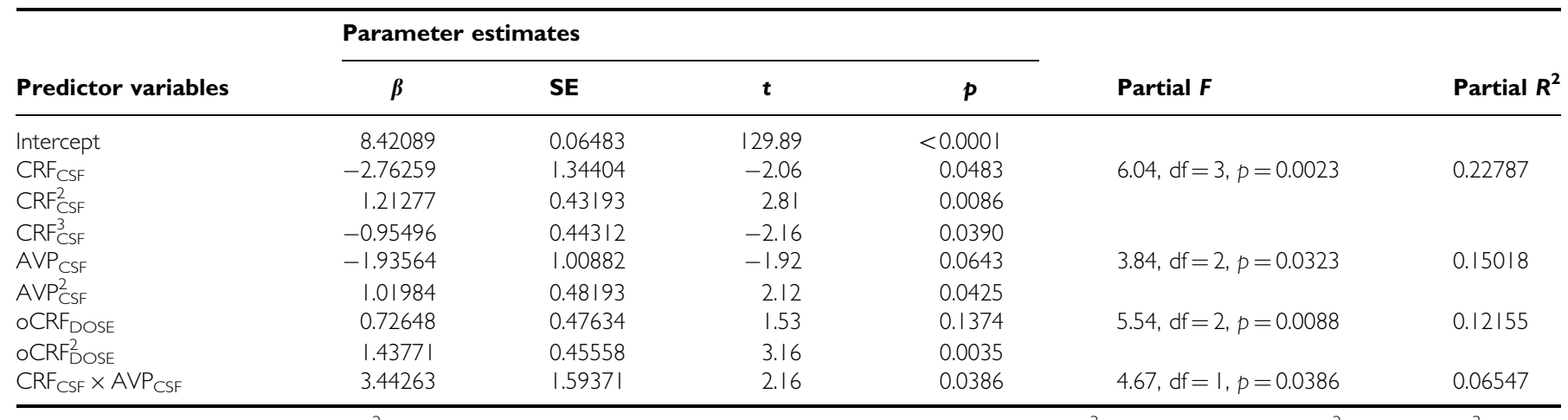

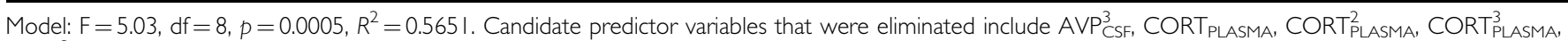

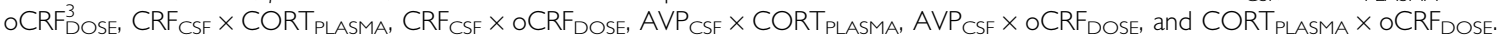

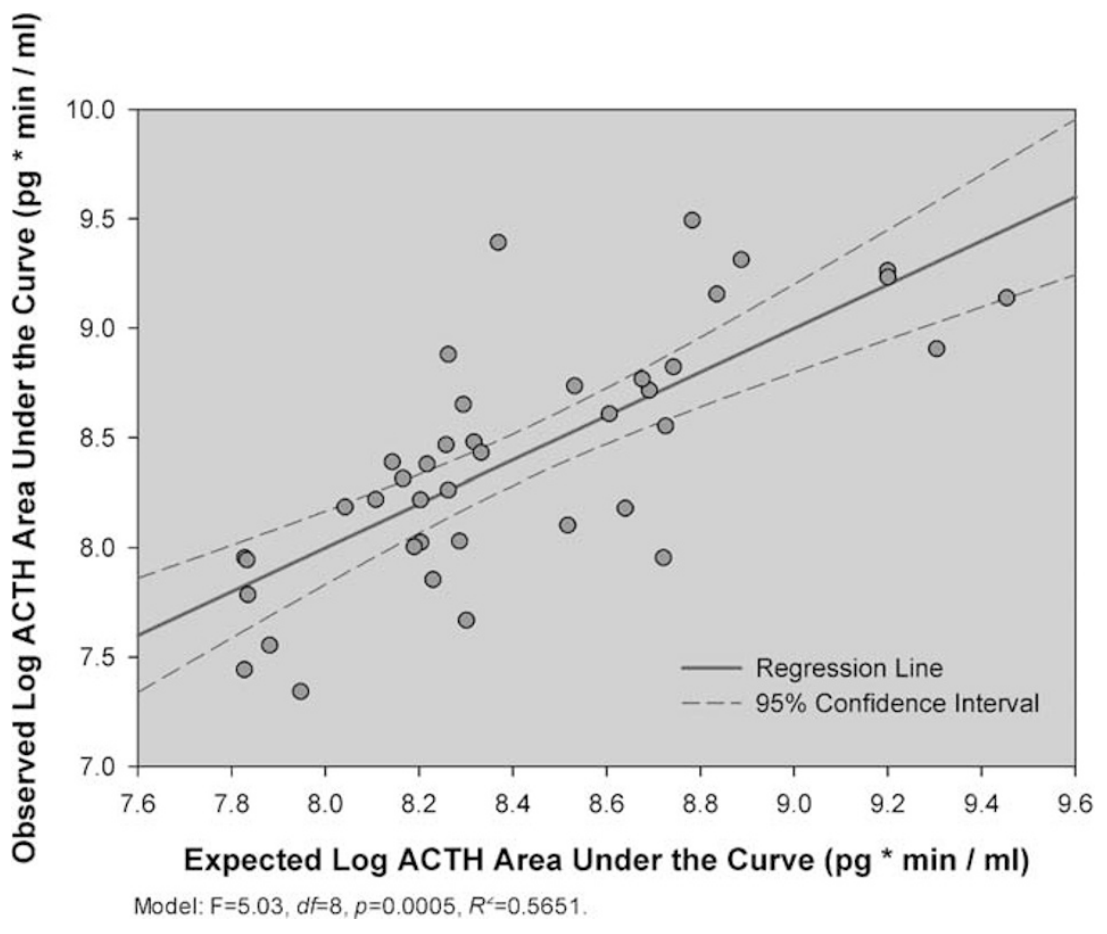

Figure I Scatter plot of the multiple regression analysis of ACTH area under the curve during the CRF stimulation test.

(Oldfield et al, 1985), analyses based upon CSF bulk flow rates may underestimate the contribution of higher CNS centers to the CRF present in lumbar CSF. Such mechanisms may underlie the numerous reports of elevated CSF CRF concentrations in patients with stress-related psychiatric disorders (cf Newport and Nemeroff, 2001 for a review) and the association of higher CSF CRF concentrations with brain activation patterns in experimental animals that accompany fearful temperament (Kalin et al, 2000).

Preclinical evidence indicates that CSF CRF may also be more directly related to HPA axis activity than anticipated. Intraventricular administration of CRF in a primate model was found to stimulate HPA axis activation (Rock et al, 1984), and bilateral ablation of the parvocellular nuclei was observed to reduce CSF CRF concentrations by $50 \%$ in a rodent study (Hong et al, 1995). Although the dissociation between the circadian rhythms of CSF CRF and plasma glucocorticoids (Garrick et al, 1987; Kalin et al, 1987; Geracioti et al, 1997; Kling et al, 1994) suggests that reliable estimates of the short-term relationship between CSF CRF concentrations and HPA axis activity may be difficult, if not impossible, to obtain, the current study sought to delineate not the acute association but the long-term relationship between CSF CRF concentrations and HPA axis responsivity. Even if CSF CRF primarily originates from extrahypothalamic sources, the inverse relationship between CSF CRF concentrations and pituitary responses to CRF stimulation reported in the current study are understandable if CSF CRF concentrations are simply proportional to the activity of CRF-secreting hypothalamic neurons over time.

The pattern of association between $\mathrm{AVP}_{\mathrm{CSF}}$ and $\mathrm{ACTH}_{\mathrm{AUC}}$ follows simpler second-order kinetics but may nonetheless be more difficult to interpret. Forming a slightly U-shaped 
curve, $\mathrm{ACTH}_{\mathrm{AUC}}$ responses decrease as $\mathrm{AVP}_{\mathrm{CSF}}$ increases to its approximate mean value $(3.14 \mathrm{pg} / \mathrm{ml})$ in this sample. As $\mathrm{AVP}_{\mathrm{CSF}}$ continues to increase beyond this point, the $\mathrm{ACTH}_{\mathrm{AUC}}$ responses then begin to increase in parallel. As a secondary ACTH secretagogue, it seems intuitive that chronically elevated AVP secretion will be less likely than chronic CRF hypersecretion to produce a blunted pituitary ACTH response. Thus, the more consistent pattern of blunted ACTH response in association with CRF hypersecretion is not associated with AVP hypersecretion. The heightened ACTH responses among those patients with the highest concentrations of AVP may, in fact, reflect the capacity of AVP to facilitate CRF-induced pituitary activation even in the presence of CRF receptor downregulation. This interpretation is consistent with studies indicating that coadministration of a vasopressin analogue during the CRF stimulation test potentiates pituitary release of ACTH (Dickstein et al, 1996; Dinan et al, 1999; Scott et al, 1999).

This study's finding with respect to oCRF $\mathrm{DOSE}_{\mathrm{D}}$ raises important considerations for future studies utilizing the CRF stimulation test. The study used weight-adjusted dosing $(1 \mu \mathrm{g} / \mathrm{kg})$ in an effort to ensure equivalent pituitary stimulation for patients of various body sizes. Examination of a scatterplot of oCRF $\mathrm{DOSE}_{\mathrm{D}} v \mathrm{ACTH}_{\mathrm{AUC}}$ (data not shown) indicates that this strategy was successful up to a dose of approximately $100 \mu \mathrm{g}$ (ie patient body weight of $100 \mathrm{~kg}$ ). At doses over $100 \mu \mathrm{g}, \mathrm{ACTH}_{\mathrm{AUC}}$ increases in an exponential manner with increasing dose. The weight adjustment of oCRF doses may not, therefore, reliably equalize pituitary stimulation for patients weighing more than $100 \mathrm{~kg}$.

This study has several limitations. First, the study sample is limited to adult women of reproductive age. The findings, therefore, may not be replicable in men or women of other ages. Second, CSF peptide concentrations were measured from samples obtained $24 \mathrm{~h}$ before the CRF stimulation test was performed. Although synchronizing both procedures at 4:00 pm on consecutive days eliminates potential confounding by circadian fluctuations in CRF secretion and HPA axis activity (Motomatsu et al, 1984; Watabe et al, 1987; Salata et al, 1988; Geracioti et al, 1992; Kling et al, 1994; Kellner et al, 1995; Keenan et al, 2001), it is not certain that CSF peptide concentrations are constant from one day to the next. Furthermore, the model produced in this study comprised of afternoon samples may not accurately depict neuroendocrine function at other times in the diurnal cycle. For example, a previous study comparing morning $v s$ evening ACTH responses to AVP stimulation (Salata et al, 1988) suggests that a more pronounced positive correlation between CSF AVP concentrations and pituitary responses to CRF administration may have been observed if the clinical procedures had been conducted in the morning. Third, the study did not include an assessment of HPA axis counter-regulatory mechanisms. Although the intent of the present study was to clarify the relationship between CRF and AVP activity within the CNS and pituitary corticotroph activity, this tightly coupled relationship is nevertheless subject to complex modulatory influences of feedback and feedforward mechanisms at numerous levels within the HPA axis. These regulatory mechanisms are important considerations when interpreting CRF stimulation results as indicated by the alterations in pituitary response to CRF caused by pretreatment with metyrapone (von Bardeleben et al, 1988; Lisansky et al, 1989; Young et al, 1995) or dexamethasone (Deuschle et al, 1998; Modell et al, 1998; Rybakowski and Twardowska, 1999).

Future studies should further clarify the CNS implications of the results provided by the CRF stimulation test by linking this test not only with CSF studies but also with functional neuroimaging studies and indices of the magnitude of HPA axis feedback activity such as the dexamethasone suppression test or dexamethasone-CRF stimulation test. Studies coupled with tests of feedback activity should not be expected to provide monolithic answers that uniformly apply to all stress-related disorders. For example, it is increasingly clear that survivors of trauma frequently exhibit a dissociation of central CRF hyperactivity and adrenal dysfunction that is not witnessed in nontraumatized individuals with depression (Heim et al, 2000, 2001). Such pathophysiological subtleties will be increasingly important as secondary mechanisms such as negative feedback are incorporated into the model.

Studies linking the CRF stimulation test with functional neuroimaging techniques are currently being planned. As suitable radioligands for binding sites for CRF, AVP, cortisol, and other neuroregulators are developed, coordinated neuroendocrine/neuroimaging batteries will provide minimally invasive means that potentially offer an incremental advance beyond CSF studies. Since the source of CSF CRF remains obscure, functional imaging techniques utilizing radioligands for $\mathrm{CRF}$ receptors and other neurohormone binding sites may remedy this shortcoming of CSF studies by delineating region-specific alterations in the density and binding affinities of such CNS-binding sites. When coupled with peripheral neuroendocrine assays including the CRF stimulation test, such imaging studies will likely further elucidate the relationship between peripheral HPA axis function and central neuronal CRF activity, thereby clarifying the conclusions regarding CNS function that can be drawn from neuroendocrine window strategies including the CRF stimulation test.

\section{ACKNOWLEDGMENTS}

Supported by PHS Grant M01-RR00039 from the General Clinical Research Centers Program and NIH Grants $\mathrm{MH}-$ 58922, MH-42088, and MH-63507. The authors are grateful to Dr TJB Van Wimersma Greidanus (University of Utrecht), who supplied the antiserum for the vasopressin assay, and to Ferring Pharmaceuticals, Inc., who supplied the ovine CRF at a discounted price.

\section{REFERENCES}

Amsterdam J, Maislin G, Winokur A, Berwish N, Kling M et al (1988). The oCRH test before and after clinical recovery from depression. J Affect Disord 14: 213-222.

Apple JK, Minton JE, Parsons KM, Unruh JA (1993). Influence of repeated restraint and isolation stress and electrolyte administration on pituitary-adrenal secretions, electrolytes, and other blood constituents of sheep. J Anim Sci 71: 71-77.

Arato M, Banki CM, Bissette G, Nemeroff CB (1989). Elevated CSF CRF in suicide victims. Biol Psychiatry 25: 355-359. 
Bremner JD, Vermetten E, Mazure C (2000). Development and preliminary psychometric properties of an instrument for the measurement of childhood trauma: the early trauma inventory. Depress Anxiety 12: 1-12.

Bulbrook RD, Herian M, Tong D, Hayward JL, Swain MC, Wang DY (1973). Effect of steroidal contraceptives on levels of plasma androgen sulfates and cortisol. Lancet 1: 628-631.

Carol W, Borner A, Klinger G, Greinke C (1980). Transcortin as an indicator of estrogenic potency in oral contraceptives. Endokrinologie 75: 167-172.

Carr BR, Parker CRJ, Madden JD, MacDonald PC, Porter JC (1979). Plasma levels of adrenocorticotropin and cortisol in women receiving oral contraceptive steroid treatment. J Clin Endocrinol Metab 49: 346-349.

Coppinger TR, Minton JE, Reddy PG, Blecha F (1991). Repeated restraint and isolation stress in lambs increases pituitaryadrenal secretions and reduces cell-mediated immunity. J Anim Sci 69: 2808-2814.

Dellwo M, Beauchene RE (1990). The effect of exercise, diet restriction, and aging on the pituitary-adrenal axis in the rat. Exp Gerontol 25: 553-562.

Deuschle M, Schweiger U, Gotthardt U, Weber B, Koerner A, Schmider J et al (1998). The combined dexamethasonecorticotropin releasing hormone stimulation test is more closely associated with features of diurnal activity of the hypothalamopituitary-adrenocortical system than the dexamethasone suppression test. Biol Psychiatry 43: 762-766.

Dickstein G, DeBold CR, Gaitan D, DeCherney GS, Jackson RV, Sheldon WR et al (1996). Plasma corticotropin and cortisol responses to ovine corticotropin-releasing hormone (CRH), arginine vasopressin (AVP), CRH plus AVP, and CRH plus metyrapone in patients with Cushing's disease. J Clin Endocrinol Metab 81: 2934-2941.

Dinan TG, Lavelle E, Scott LV, Newell-Price J, Medbak S, Grossman AB (1999). Desmopressin normalizes the blunted adrenocorticotropin response to corticotropin-releasing hormone in melancholic depression: evidence of enhanced vasopressinergic responsivity. J Clin Endocrinol Metab 84: 22382240 .

First MB, Spitzer RL, Gibbon M, Williams JB (1997). Structured Clinical Interview for DSM-IV. American Psychiatric Press: Washington.

Fujimoto NY, Villanueva AL, Hopper B, Moscinski M, Rebar RW (1986). Increased adrenocortical responsiveness to exogenous ACTH in oral contraceptive users. Adv Contraception 2: 343353.

Garrick NA, Hill JL, Szele FG, Tomai TP, Gold PW, Murphy DL (1987). Corticotropin-releasing factor: a marked circadian rhythm in primate cerebrospinal fluid peaks in the evening as is inversely related to the cortisol circadian rhythm. Endocrinology 121: 1329-1334.

Geracioti TD, Loosen PT, Orth DN (1997). Low cerebrospinal fluid corticotropin-releasing hormone concentrations in eucortisolemic depression. Biol Psychiatry 42: 166-174.

Geracioti TD, Orth DN, Ekhator NN, Blumenkopf B, Loosen PT (1992). Serial cerebrospinal fluid corticotropin-releasing hormone concentrations in healthy and depressed humans. J Clin Endocrinol Metab 74: 1325-1330.

Gold P, Chrousos G, Kellner C, Post R, Roy A, Augerinas P et al (1984). Psychiatric implications of basic and clinical studies with corticotropin-releasing factor. Am J Psychiatry 141: 619-627.

Hanada K, Yamada N, Shimoda K, Takahashi K, Takahashi S (1985). Direct radioimmunoassay of cortisol in saliva and its application to the dexamethasone suppression test in affective disorders. Psychoneuroendocrinology 10: 193-201.

Hauger RL, Shelat SG, Redei EE (2002). Decreased corticotropinreleasing factor receptor expression and adrenocorticotropic hormone responsiveness in anterior pituitary cells of WistarKyoto rats. J Neuroendocrinol 14: 126-134.

Heim C, Ehlert U, Rexhausen J (1997). Psychoendocrinological observations in women with chronic pelvic pain. In: Yehuda R, McFarlane A (eds). Psychobiology of Posttraumatic Stress Disorder. New York Academy of Sciences: New York. pp 456458.

Heim C, Newport DJ, Bonsall R, Miller AH, Nemeroff CB (2001). Altered pituitary-adrenal axis responses to provocative challenge tests in adult survivors of childhood abuse: the role of comorbid depression. Am J Psychiatry 158: 575-581.

Heim C, Newport DJ, Heit S, Graham YP, Wilcox M, Bonsall R et al (2000). Increased pituitary-adrenal and autonomic responses to stress in adult women after sexual and physical abuse in childhood. JAMA 284: 592-597.

Holsboer F, Gerken A, Stalla GK, Mueller OA (1987). Blunted aldosterone and ACTH release after human CRH administration in depressed patients. Am J Psychiatry 144: 229-231.

Hong SK, Gold PW, Herkenham M (1995). Hypothalamic paraventricular nucleus lesions decrease corticotropin releasing hormone in the CSF and elevate TH in mRNA in the locus ceruleus. Soc Neurosci Abstr 19: 762.

Kalin NH, Shelton SE, Barksdale CM, Brownfield MS (1987). A diurnal rhythm in cerebrospinal fluid corticotropin-releasing hormone different from the rhythm of pituitary-adrenal activity. Brain Res 426: 385-391.

Kalin NH, Shelton SE, Davidson RJ (2000). Cerebrospinal fluid corticotropin-releasing hormone levels are elevated in monkeys with patterns of brain activity associated with fearful temperament. Biol Psychiatry 47: 579-585.

Kathol R, Jaeckle R, Lopez J, Mullter W (1989). Consistent reduction of ACTH responses to stimulation with CRF, vasopressin and hypoglycemia in patients with depression. $\mathrm{Br} J$ Psychiatry 155: 468-478.

Keck ME, Holsboer F (2001). Hyperactivity of CRH neuronal circuits as a target for therapeutic interventions in affective disorders. Peptides 22: 835-844.

Keenan DM, Licinio J, Veldhuis JD (2001). A feedback-controlled ensemble model of the stress-responsive hypothalamo-pituitaryadrenal axis. Proc Natl Acad Sci USA 98: 4028-4033.

Kellner M, Herzog L, Holsboer F, Wiedemann K (1995). Circadian changes in the sensitivity of the corticotropin-releasing hormone-stimulated HPA system after arginine vasopressin and atrial natriuretic hormone in human male controls. Psychoneuroendocrinology 20: 515-524.

Kemppainen RJ, Filer DV, Sartin JL, Reed RB (1986). Ovine corticotrophin-releasing factor in dogs: dose-response relationships and effects of dexamethasone. Acta Endocrinol 112: 12-19.

Kirschbaum C, Kudielka BM, Gaab J, Schommer NC, Hellhammer DH (1999). Impact of gender, menstrual cycle phase, and oral contraceptives on the activity of the hypothalamus-pituitaryadrenal axis. Psychosom Med 61: 154-162.

Kirschbaum C, Pirke KM, Hellhammer DH (1995). Preliminary evidence for reduced cortisol responsivity to psychological stress in women using oral contraceptive medication. Psychoneuroendocrinology 20: 509-514.

Kirschbaum C, Platte P, Pirke KM, Hellhammer DH (1996). Adrenocortical activation following stressful exercise: further evidence for attenuated free cortisol responses in women using oral contraceptives. Stress Med 12: 137-143.

Kleinbaum DG, Kupper LL, Muller KE, Nizam A (1998). Applied Regression Analysis and other Multivariable Methods, 3rd edn. Duxbury Press: Pacific Grove, CA.

Kling MA, DeBellis MD, O’Rourke DK, Listwak SJ, Geracioti TD, McCutcheon IE et al (1994). Diurnal variation of cerebrospinal fluid immunoreactive corticotropin-releasing hormone levels in healthy volunteers. J Clin Endocrinol Metab 79: 233-239. 
Kling MA, Rubinow DR, Doran AR, Roy A, Davis CL, Calabrese JR et al (1993). Cerebrospinal fluid immunoreactive somatostatin concentrations in patients with Cushing's disease and major depression: relationship to indices of corticotropin-releasing hormone and cortisol secretion. Neuroendocrinology 57: 79-88.

Kosowska B (1992). The effect of genetic variability (degree of homozygosity) on serum levels of the anterior pituitary hormones prolactin, corticotropin, and growth hormone in rats. Biochem Genet 30: 561-589.

Lennard DE, Eckert WA, Merchenthaler I (1993). Corticotropinreleasing hormone neurons in the paraventricular nucleus project to the external zone of the median eminence: a study combining retrograde labeling with immunocytochemistry. $J$ Neuroendocrinol 5: 175-181.

Lisansky J, Peake GT, Strassman RJ, Qualls C (1989). Augmented pituitary corticotropin response to a threshold dosage of human corticotropin-releasing hormone in depressives pretreated with metyrapone. Arch Gen Psychiatry 46: 641-649.

Meulenberg PM, Hofman JA (1990). The effect of oral contraceptive use and pregnancy on the daily rhythm of cortisol and cortisone. Clin Chim Acta 190: 211-221.

Modell S, Lauer CJ, Schreiber W, Huber J, Krieg JC, Holsboer F (1998). Hormonal response pattern in the combined DEX-CRH test is stable over time in subjects at high familial risk for affective disorders. Neuropsychopharmacology 18: 253-262.

Motomatsu T, Takahashi H, Ibayashi H, Nobunaga M (1984). Human plasma proopiomelanocortin $\mathrm{N}$-terminal peptide and adrenocorticotropin: circadian rhythm, dexamethasone suppression, and corticotropin-releasing hormone stimulation. J Clin Endocrinol Metab 59: 495-498.

Nemeroff CB (1996). The corticotropin-releasing factor (CRF) hypothesis of depression: new findings and new directions. Mol Psychiatry 1: 336-342.

Newport DJ, Nemeroff CB (2001). Hypothalamic-pituitary-adrenal (HPA) axis: normal physiology and disturbances in depression. In: Thakore JH (ed). Physical Consequences of Depression. Wrightson Biomedical Publishing, Ltd.: Petersfield, England. pp 1-22.

Newport DJ, Stowe ZN, Nemeroff CB (2002). Parental depression: animal models of an adverse life event. Am J Psychiatry 159: $1265-1283$.

Nickelsen T, Lissner W, Schoffling K (1989). The dexamethasone suppression test and long-term contraceptive treatment: measurement of ACTH or salivary cortisol does not improve the reliability of the test. Exp Clin Endocrinol 94: 275-280.
Oldfield EH, Schulte HM, Chrousos GP, Rock JP, Kornblith PL, O'Neill DL et al (1985). Active clearance of corticotropinreleasing factor from the cerebrospinal fluid. Neuroendocrinology 40: $84-87$.

Plotsky P, Owens MJ, Nemeroff CB (1998). Psychoneuroendocrinology of depression: hypothalamic-pituitary-adrenal axis. Psychiatr Clin North Am 21: 293-307.

Rock JP, Oldfield EH, Schulte HM, Gold PW, Kornblith PL, Loriaux L et al (1984). Corticotropin releasing factor administered into the ventricular CSF stimulates the pituitary-adrenal axis. Brain Res 323: 365-368.

Rybakowski JK, Twardowska K (1999). The dexamethasone/ corticotropin-releasing hormone test in depression in bipolar and unipolar affective illness. J Psychiatr Res 33: 363-370.

Salata RA, Jarrett DB, Verbalis JG, Robinson AG (1988). Vasopressin stimulation of adrenocorticotropin hormone (ACTH) in humans: in vivo bioassay of corticotropin-releasing factor (CRF) which provides evidence for CRF mediation of the diurnal rhythm of ACTH. J Clin Invest 81: 766-774.

Scott LV, Dinan TG (1998). Vasopressin and the regulation of hypothalamic-pituitary-adrenal axis function: implications for the pathophysiology of depression. Life Sci 62: 1985-1998.

Scott LV, Medbak S, Dinan TG (1999). Desmopressin augments pituitary-adrenal responsivity to corticotropin-releasing hormone in subjects with chronic fatigue syndrome and in healthy volunteers. Biol Psychiatry 45: 1447-1454.

Shapiro SS, Wilks MB (1965). An analysis of variance test for normality (complete samples). Biometrika 52: 591-611.

Smith M, Davidson J, Ritchie J (1989). The corticotropin releasing hormone test in patients with post-traumatic stress disorder. Biol Psychiatry 26: 349-355.

von Bardeleben U, Stalla GK, Mueller OA, Holsboer F (1988). Blunting of ACTH response to human CRH in depressed patients is avoided by metyrapone pretreatment. Biol Psychiatry 24: 782786.

Watabe T, Tanaka K, Kumagae M, Itoh S, Hasegawa M, Horiuchi T et al (1987). Diurnal rhythm of plasma immunoreactive corticotropin-releasing factor in normal subjects. Life Sci 40: 1651-1655.

Young EA, Akil Y, Haskett RF, Watson SJ (1995). Evidence against changes in corticotroph CRF receptors in depressed patients. Biol Psychiatry 37: 355-363.

Young EA, Watson SJ, Kotun J (1990). Beta-lipotropin-betaendorphin response to low-dose ovine corticotropin releasing factor in endogenous depression. Arch Gen Psychiatry 47: 449457. 